\title{
THERMO-HYDRAULIC BEHAVIOUR OF COOLANT IN NUCLEAR REACTOR VVER-440 UNDER REFUELLING CONDITIONS
}

\author{
PAULECH Juraj ${ }^{1}$, KUTIŠ Vladimír ${ }^{1}$, GÁLIK Gabriel ${ }^{1}$, \\ JAKUBEC Jakub ${ }^{1}$, SEDLÁR Tibor ${ }^{1}$ \\ ${ }^{I}$ Slovak University of Technology in Bratislava, Faculty of Electrical Engineering and Information Technology, \\ Department of Applied Mechanics and Mechatronics, Ilkovičova 3, 81219 Bratislava, Slovak Republic, \\ email: juraj.paulech@stuba.sk
}

\begin{abstract}
The paper presents the numerical simulation of thermo-hydraulic behaviour of coolant in the VVER440 nuclear reactor under standard outage conditions. Heating-up and flow of coolant between the reactor pressure vessel and spent fuel storage pool are discussed.
\end{abstract}

KEYWORDS: CFD analysis, ANSYS CFX, Nuclear Reactor, VVER-440, refuelling

\section{Introduction}

Thermo-hydraulic conditions in nuclear reactors are important not only in the operation mode but also under refuelling and outage conditions. During outages, several components of the nuclear reactor system (NR) are flooded by coolant [1]. These interconnected components are the reactor vessel (RV), reactor pool (RP) and spent fuel storage pool (SFSP). Values of pressure and temperature are significantly lower than in the operating mode (above $12 \mathrm{MPa}$ ), because the system is operated under atmospheric pressure conditions. For the thermal behaviour, only residual heat of fuel assemblies is considered. This residual heat is caused by decay of the secondary fission products and it is necessary to ensure that the cooling process during outages of the reactor continues. The thermo-hydraulic conditions are important also for outage conditions, because:

- $\quad$ reactor vessel is interconnected with reactor pool and spent fuel storage pool (flooded by coolant)

- fuel assemblies with their residual heat are situated in the reactor vessel and in the spent fuel storage pool

- thermal and hydraulic influence between reactor vessel and pools occurs

- transfer of impurities may occur

The paper presents thermo-hydraulic conditions calculated using Computational Fluid Dynamics - CFD code [2, 3] ANSYS CFX in nuclear reactor VVER-440 [4] during outage conditions where the above mentioned phenomena are discussed.

\section{CFD Analysis}

The CFD analysis was performed considering the geometric model in Fig. 1, that represents the volume of the coolant in the system during outage conditions. 


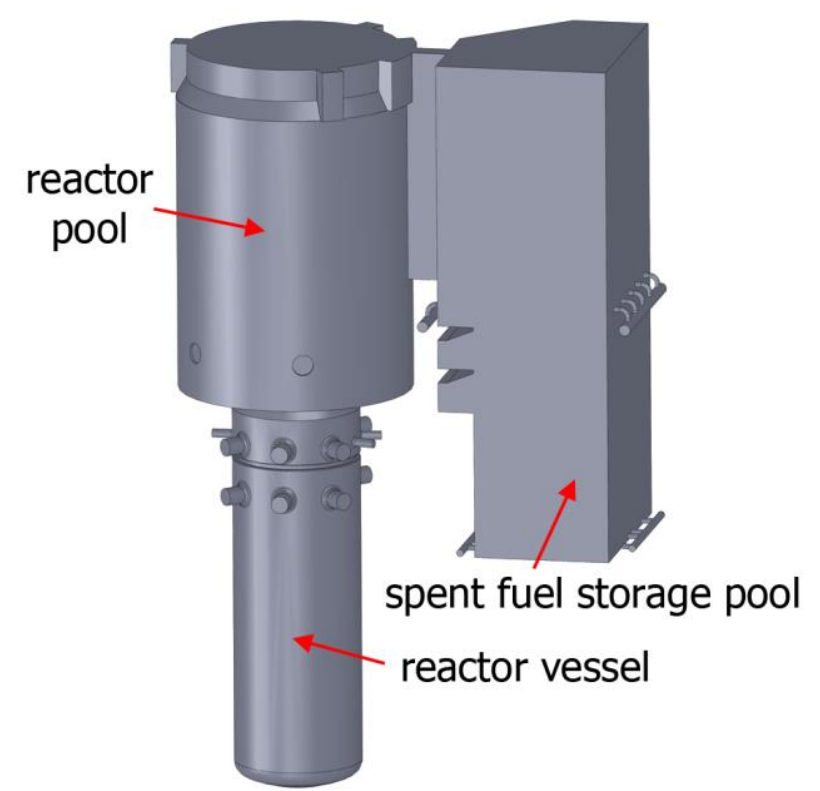

Fig. 1 Geometric model of the system during outage conditions

The fuel assemblies and their residual thermal power were situated in the RV (residual thermal power from fuel assemblies that were in operation right before the outage) and in SFSP (residual thermal power from fuel assemblies stored from previous operations and outages). The residual thermal power within the RV had a value of approx. 4.4 MW total. Cooling of the $\mathrm{RV}$ was provided by natural convection using loop through one steam generator (over $40 \mathrm{~kg} / \mathrm{s}$ of coolant flow, temperature at the cold nozzle was $35^{\circ} \mathrm{C}$ ). Forced convection was considered only in SFSP represented by two inlets and two outlets, with mass flow approx. equal to 100 $\mathrm{kg} / \mathrm{s}$ in total and inlet temperature of $35{ }^{\circ} \mathrm{C}$, Fig. 2. Residual thermal power in the fuel assemblies within the SFSP with a value of only approx. $0.25 \mathrm{MW}$ in total due to the fuel assemblies being stored in SFSP for longer periods of time resulting in reduced activity. The parts of the system with fuel assemblies (RV and SFSP) were not modelled in detail but they were modelled as two components with porous properties. These simplifications were necessary due to the complexity of the computationally intensive model.
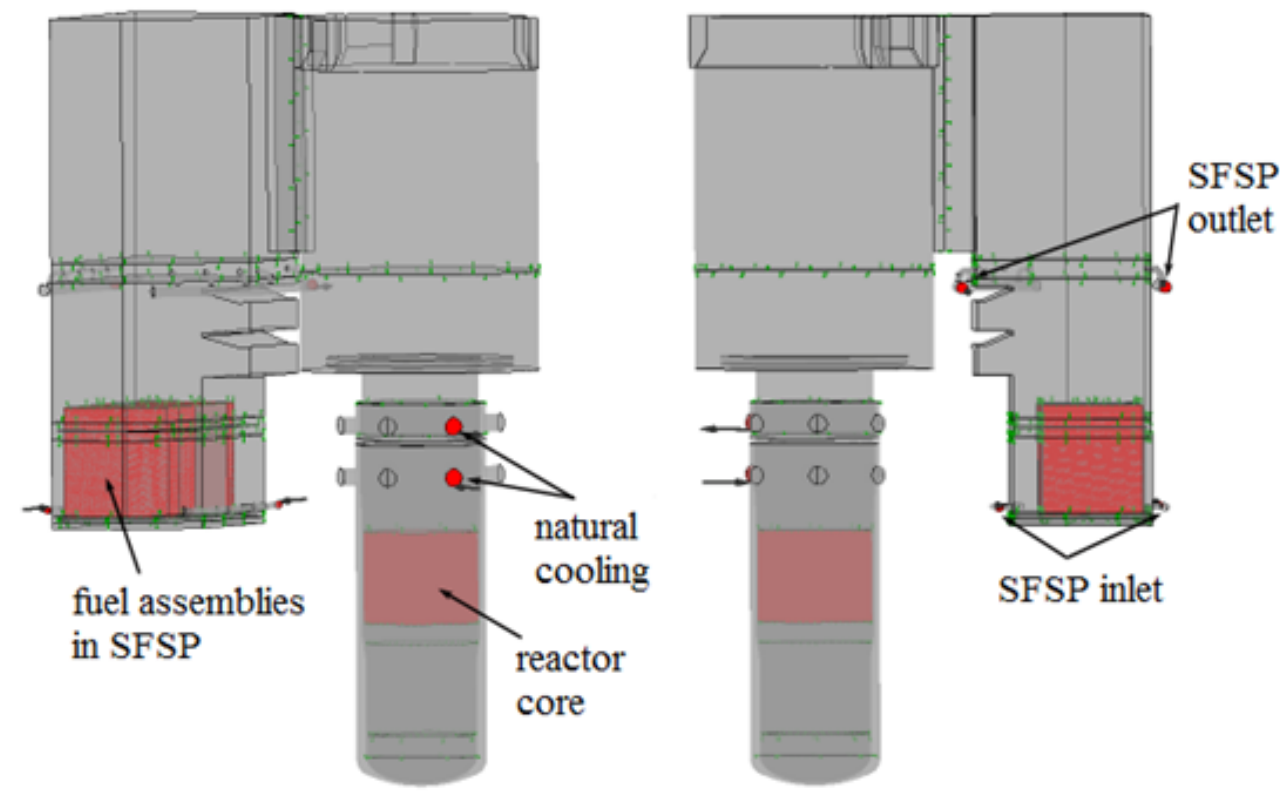

Fig. 2 Boundary conditions of the model 
The model was discretized by approx. 2.1 mil. elements, Fig. 3.

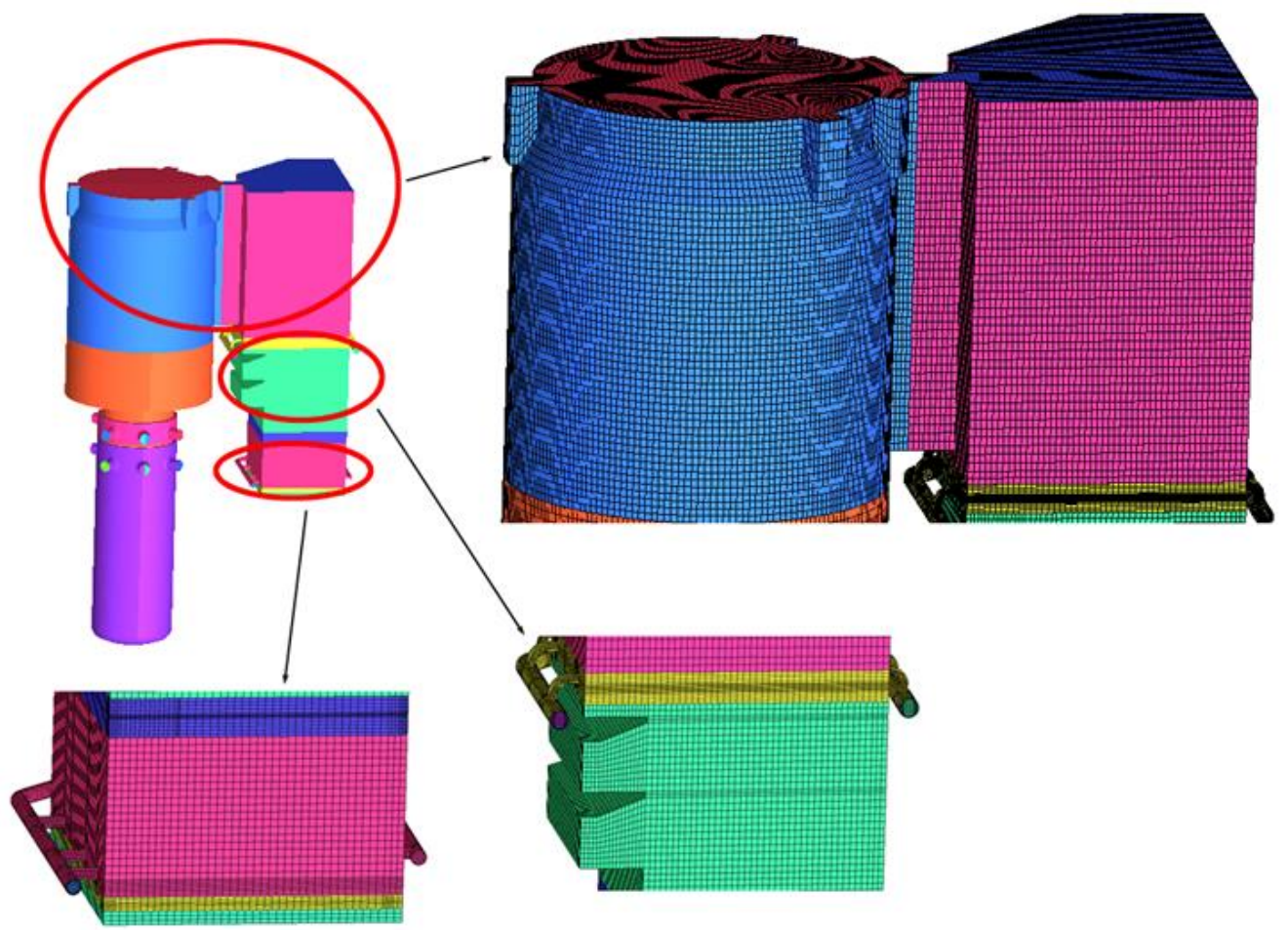

Fig. 3 Model mesh

The parameters of the simulations were:

- $\quad$ steady-state analysis

- $\quad$ shear stress transport turbulent model [5]

- 1 second physical timescale for fluid

- convergence control by value $1 \times 10^{-4}$ residual RMS

Numerical solution of the CFD is based on calculation of Reynolds Averaged Navier Stokes differential equations for continuity, momentum and energy of the fluid flow. Turbulent behaviour of the flow was not modelled at the level of finite volume mesh but was modelled numerically by shear stress transport turbulent model. However, the analysis was a steady-state case (it was calculated using pseudo-time iterative method where thousands of iterations were necessary to achieve a converged solution). The obtained results are show in Fig. 4, 5 and 6. Fig. 4 shows the temperature distribution at the longitudinal cross-section of the model. Fig. 5 shows temperature distribution at the chosen lateral cross-sections of the model. Fig. 6 shows the velocity distribution. 


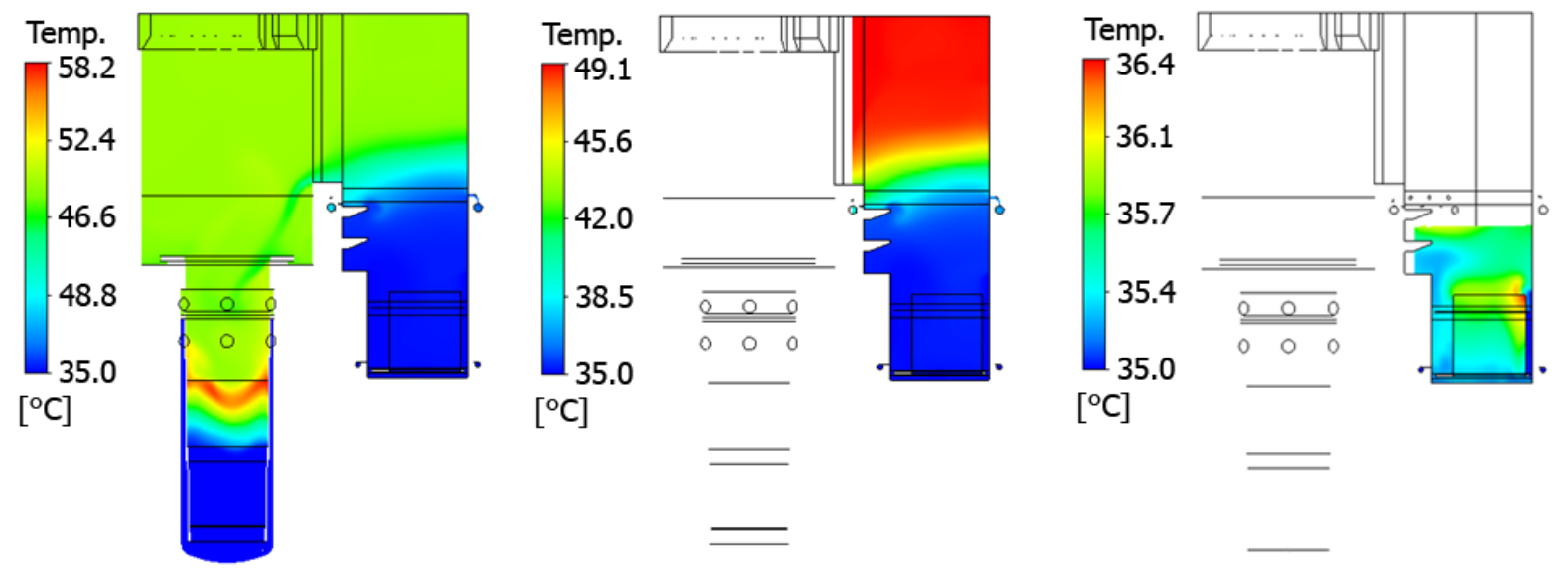

Fig. 4 Temperature distribution at longitudinal cross-section
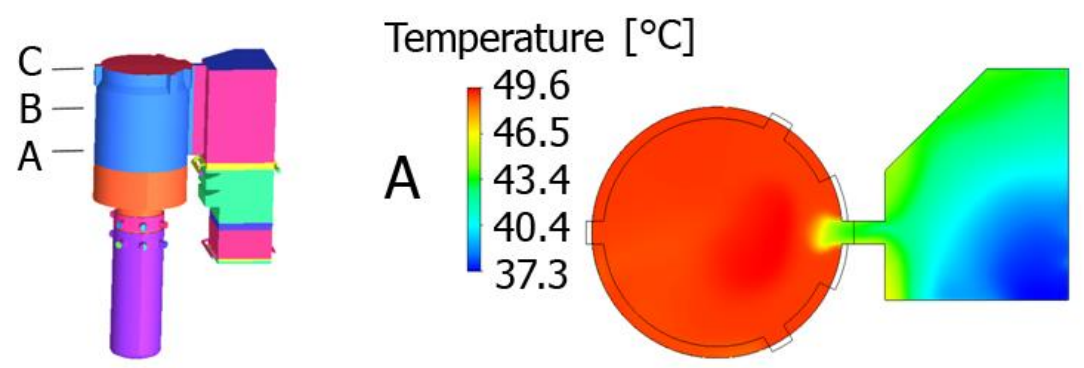

Temperature $\left[{ }^{\circ} \mathrm{C}\right]$

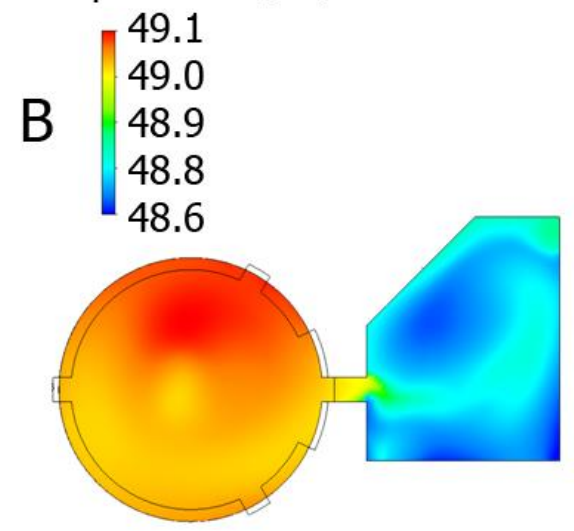

Temperature $\left[{ }^{\circ} \mathrm{C}\right]$

49.2
$\mathrm{C} \quad 49.1$
49.0
48.9

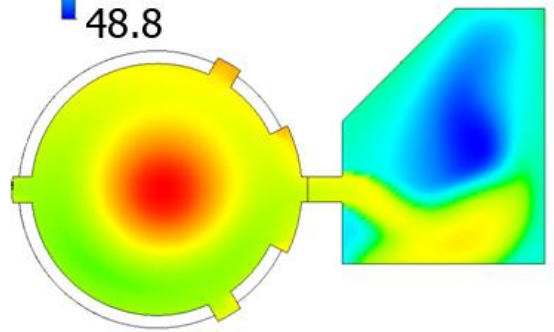

Fig. 5 Temperature distribution at chosen lateral cross-sections 


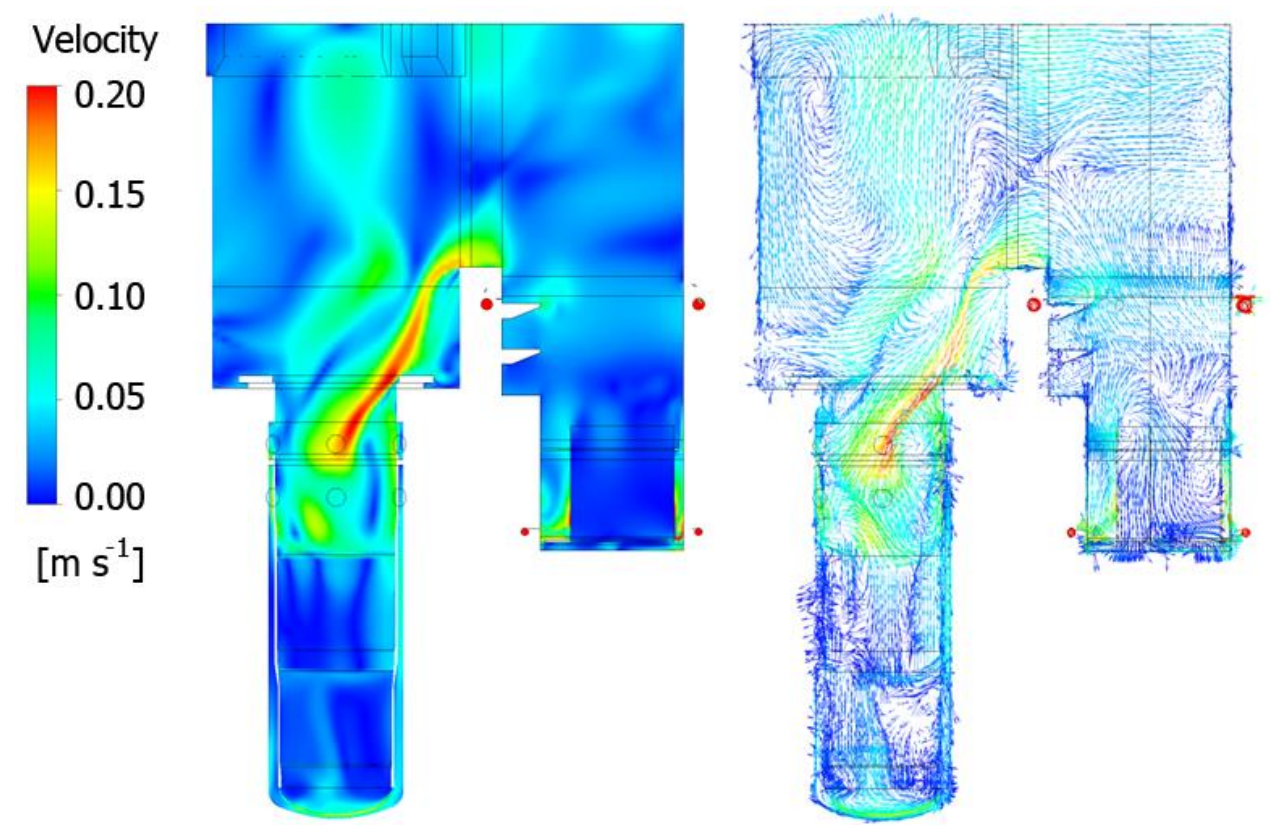

Fig. 6 Velocity distribution at cross-section

As it can be seen from these results, the flow of coolant is relatively slow and mixing of coolant between SFSP, RP and RV is subtle. But there is considerable bidirectional flow through the interconnecting channel between RP and SFSP where the coolant from RP enters into the SFSP at the top part and leaves the SFSP at the bottom part of the channel. Maximum heat-up of the coolant is approx. $23{ }^{\circ} \mathrm{C}$ located right above the core of the reactor. As it can be assumed from the values of residual heat in R and in SFSP dominant thermal effect is caused by reactor core, the influence of SFSP is low.

\section{Discussion of results}

The results show that a mutual influence between RV, RP and SFSP is evident especially in coolant temperature distribution, but the flow of coolant is relatively slow across the whole system and mixing of the coolant between SFSP, RP and RV is subtle.

\section{Conclusion}

The paper presented computational analysis of the thermo-hydraulic conditions of coolant during outages. The results show that flow of coolant under these conditions is relatively slow and mixing of the coolant between individual components of the interconnected system is not significant.

\section{ACKNOWLEDGEMENT}

This work was supported by the Slovak Research and Development Agency under the contract No. APVV-0246-12 and APVV-14-0613, by Scientific Grant Agency of the Ministry of Education of Slovak Republic and the Slovak Academy of Sciences VEGA grant No. $1 / 0228 / 14$ and 1/0453/15. Authors are also grateful to the HPC Centre at the Slovak University of Technology in Bratislava, which is a part of the Slovak Infrastructure of High Performance Computing (SIVVP project, ITMS code 26230120002, funded by the European Regional Development Funds), for the computational time and resources made available. 


\section{REFERENCES}

[1] N. E. Todreas, M. S. Kazimi. Nuclear Systems Volume I: Thermal Hydraulic Fundamentals. CRC Press, 2011, 2nd edition. ISBN 1439808872.

[2] H. Versteeg, W. Malalasekera. An Introduction to Computational Fluid Dynamics: The Finite Volume Method, Prentice Hall, 2007, 2nd edition. ISBN 0131274988.

[3] N. Kapilan, M. M. Gowda, H. N. Manjunath. Computational Fluid Dynamics Analysis of an Evaporative Cooling System. Journal of Mechanical engineering - Strojnicky časopis, 2016 (66), No. 2., 117 - 124. ISSN 0039-2472.

[4] V. Kutiš, J. Jakubec, J. Paulech, G. Gálik, T. Sedlák. CFD analysis of downcomer of nuclear reactor VVER 440. Journal of Mechanical engineering - Strojnicky časopis, 2016 (66), No. 2, 55 - 62. ISSN 0039-2472.

[5] D. C. Wilcox. Turbulence Modeling for CFD. D C W Industries, 2006, 3rd edition. ISBN 1928729088 